\title{
CRFM: AN APPLICATION OF THE FUZZY LOGIC IN APELL PROGRAMME
}

\author{
C. COSENZA, G. SANDRES, P. SOUZA JUNIOR \& E. SIGGETE \\ Department of Production Engineer, Federal University of Rio de Janeiro, Brazil
}

\begin{abstract}
The Awareness and Preparedness for Emergencies at Local Level (APELL) Programme was initiated in the late1980s in response to a number of chemical accidents that resulted in deaths and injuries, environmental damage, and extensive economic consequences in the surrounding communities. Initially, the APELL Programme focused on assisting decision-makers and technical personnel in improving community awareness of industrial hazards and in preparing response plans for chemical accidents. Nowadays, it is also applicable to natural hazards. This paper aims to provide to community, locallevel institutions, industry, experts and other stakeholders a tool, using Fuzzy Relation, the Community Risk Fuzzy Model (CRFM) to estimate the various types of risk they are exposed to, supporting the decision-making process, especially as to whether or not further assessments are needed. This tool will be developed based on an existing one, named Community Risk Profile (CRP), of the United Nations Environment Programme (UNEP). An application of CRFM will be presented using three communities at risk of flooding located in the metropolitan area of the City of Rio de Janeiro, Brazil.

Keywords: APELL, Brazil, CRFM, emergency, flood risk, Fuzzy Logic, hazards, UNEP.
\end{abstract}

\section{INTRODUCTION}

From the 1960s onwards, the chemical and petrochemical industries contributed strongly to the increase in potential accidents, due to the expansion of the scale of processing plants that rose rapidly for several decades, for economic reasons [1]. During the 1970s and 1980s, major accidents occurred at several locations all over the world, with heavy losses in terms of human lives and corporate assets, in addition to direct impacts on local eco-systems that resulted in irreparable damage for society [2].

These accidents spurred these industries to seek efficient mechanisms that would upgrade their operations, with fewer faults and less serious damages, identifying problems before major accidents occur, as well as paying closer attention to planning future response actions [3]. So, the accident prevention and emergency response planning areas became controversial aspects, due to a number of chemical accidents that resulted in deaths and injuries, environmental damage, and extensive economic consequences in the surrounding communities whose spatial distribution varied widely. In the late 1980s, The Awareness and Preparedness for Emergencies at Local Level (APELL) Programme was initiated by United Nations Environment Programme (UNEP) to assist communities with chemical hazards in preventing and preparing for industrial accidents. It is a methodological tool focusing on the local level for identifying possible industrial hazards, raising awareness, and establishing or building local capacity for immediate, multi-party responses in the event that an emergency occurs. The goal of APELL is to promote a community-oriented framework to identify and create 
awareness of risks in industrialized communities to initiate measures for risk reduction and mitigation, and to develop coordinated preparedness between industries, local authorities, and communities by building local partnerships between stakeholders.

One of the first steps in reducing community vulnerability to accidents and disasters is to assess the different hazards present in a community. The Multi-Hazard Matrix system is a simple tool that can be used for initial community self-assessment of existing risks. The approach proposed in the Multi-Hazard Matrix is a simplified version of the methodology used in the Community Risk Profile (CRP) Tool developed by INERIS for UNEP and visually presents information on various risks within the community. The CRP tool [4] provides communities with a means of making a rough estimate of various types of risks they are exposed to, supporting the decision-making process, especially as to whether or not further assessments are needed. The CRP is not, therefore, a risk assessment tool. It is a tool that will provide users with a qualitative approach to characterize an expected level of risk and thus decide on the necessity for further assessment. It is also a tool that can be used to support awareness raising and capacity-building activities.

This paper aims to provide to authorities a risk classification tool, using Fuzzy Relation Community Risk Fuzzy Model (CRFM), to optimize the investments concerning to life preservation in communities exposed to risk of flooding, supporting the decision-making process. This tool will be developed based on the methodology used in the CRP. An application of new tool will be accomplished.

\section{APELL PROGRAMME}

The APELL Programme uses a Multi-Hazard Matrix [5] which is a hazard-rating tool that uses a set of ten criteria to judge the type(s) and the magnitude(s) of the risks that a given community is exposed to. Each hazard source identified is assessed using ten different risk criteria, and assigned a number between 1 and 5 for each risk criterion. A 1 is assigned for a favorable situation (such as a low hazard, low level of vulnerability, or a sufficient level of risk control), and a 5 is assigned for an unfavorable situation (such as a frequently occurring hazard, or lack of protective measures). If there is no hazard source present in the study area,

\begin{tabular}{|c|c|c|c|c|c|c|c|c|c|c|}
\hline Risk Criteria & & 苞 & 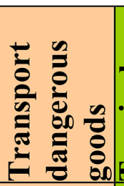 & 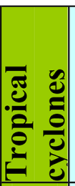 & 朂 & $\frac{0}{3}$ & 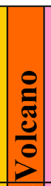 & 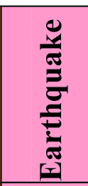 & 营 & 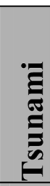 \\
\hline Presence & $0-5$ & 5 & 5 & 5 & 5 & 5 & 5 & 5 & 5 & 5 \\
\hline Intensity & $1-5$ & 5 & 5 & 5 & 5 & 5 & 5 & 5 & 5 & 5 \\
\hline Frequency & $1-5$ & 5 & 5 & 5 & 5 & 5 & 5 & 5 & 5 & 5 \\
\hline Elements at Risk & $1-5$ & 5 & 5 & 5 & 5 & 5 & 5 & 5 & 5 & 5 \\
\hline Vulnerability & $1-5$ & 5 & 5 & 5 & 5 & 5 & 5 & 5 & 5 & 5 \\
\hline $\begin{array}{ll}\text { Knowledge } & \text { of } \\
\text { Risk } & \end{array}$ & $1-5$ & 1 & 5 & 5 & 5 & 5 & 5 & 5 & 5 & 5 \\
\hline Prevention & $1-5$ & 5 & 5 & 5 & 5 & 5 & 5 & 5 & 5 & 5 \\
\hline Protection & $1-5$ & 5 & 5 & 5 & 5 & 5 & 5 & 5 & 5 & 5 \\
\hline $\begin{array}{l}\text { Emergency } \\
\text { Planning }\end{array}$ & $1-5$ & 5 & 5 & 5 & 5 & 5 & 5 & 5 & 5 & 5 \\
\hline Resilience & $1-5$ & 5 & 5 & 5 & 5 & 5 & 5 & 5 & 5 & 5 \\
\hline
\end{tabular}

Figure 1: Multi-hazard matrix. 
the user will set the presence criterion to zero (0), indicating "absence" of any hazard source. The Multi-Hazard Matrix is represented as in Fig.1.

The Multi-Hazard Matrix is an information tool that can be used by community, stakeholders, industry, and local institutions to indicate which sort of hazard a community is exposed to. The methodology used presents sophistication on the risk conception because it also considers the community information and knowledge degree of the risk that it is exposed to, the predictability of the impact, the size of the community, among other factors that are not contemplated on the simplified mathematical expression that represents risk. The matrix is filled out according to the values obtained through the CRP tool which has a spread sheet with several questions for each risk criterion.

\section{COMMUNITY RISK PROFILE TOOL}

According to CRP Tool guide, the CRP was developed to provide communities with a means of making a rough estimate of various types of risks they are exposed to, supporting the decision-making process, especially as to whether or not further assessments are needed. The CRP tool is not, therefore, a risk assessment tool. It is a tool that will provide users with a qualitative approach to characterize an expected level of risk and thus decide on the necessity for further assessment. It is also a tool that can be used to support awareness raising and capacity-building activities. It was designed for a range of users involved in risk assessment or community management, with a focus on local authorities responsible for disaster-related issues and land-use planning, as well as on insurers and aid agencies wishing to investigate risk in a given community area. Industry too will find parts of the relevant CRP tool. The CRP is produced automatically once the answers are being provided to the questions in the various spreadsheets. Each hazard identified and each criterion considered in the Multi-Hazard Matrix has a spreadsheet with specific questions to help characterize the risks associated with the different types of hazards. Each specific question is related to a mathematical equation, generally based on arithmetic average or on probability theory. Once the questions are answered, the equations calculate automatically a score for the criterion measured on a scale of 0 ("absence" of any hazard source) to 5 .

When a hazard source is present, the presence of criterion is set to 5 and all of the other criteria are then assessed on a scale of 1 to 5, indicating a favorable or unfavorable situation. The CRP tool is an excellent resource to obtain a detailed situation of a community. It specifically highlights the vulnerabilities of the community under study. When we have a scenario where several communities are potentially exposed to hazards, the governments set investment priorities according to the needs. A simple comparison of CRP spreadsheets does not faithfully rate the communities due to the following reasons:

- Most of the questions are answered in a deterministic way (crisp). Thus questions like: "Is the community in a coastal area?" and "Is there warning in case of flood?" have "yes" or "no" as answers, not taking into account the distance from the community to the coast or the amount of alarms distributed in the community. In this manner, two communities will have the same risk score, regardless their actual distance to the sea or the number of alarms.

- The questions included in the same risk criterion have the same importance in the calculation, regardless their relevance. The following question: "Is the region or the upstream area subject to intense rain episodes?" Has the same weight than the question "Are parts of the upstream soil naturally impervious?" In this case, it is necessary to assign weights for a better assessment. 
- The final result for each criterion reaches the maximum value of 5; however, when the values of each question in the spread sheet are added, this value is exceeded, but automatically reduced to 5 , distorting the result.

For community rating, according to their degree of exposure to risks, a more realistic approach in terms of comparison of risk criteria is needed. To this end, using a tool with Fuzzy Logic can solve the above-mentioned problems in a simplified manner.

\section{COMMUNITY RISK FUZZY MODEL}

The concepts and information presented by the Multi-Hazard Matrix and the need of a more realistic community comparison encouraged the development of the CRFM tool, which provides an indicator for measuring the level of risk protection (PRL) identified in a community. The CRFM tool allows comparing different communities exposed to the same type of risk and rate them from the most to the less severely affected.

The CRFM tool can be used to guide the authorities on their decision on where and how to spend the available resources to mitigate or, if possible, eliminate the identified risk. In this study, we considered just one column of the UNEP Multi-Hazard Matrix (flooding), i.e., just one kind of risk. All criteria were assessed using Fuzzy Logic.

\subsection{The problem}

The CRFM tool developed in the present paper analyses particularly flooding. This risk was chosen because every year about 195 million people in more than 90 countries, including Brazil, are exposed to catastrophic flooding. According to APELL manual, of all natural disasters, floods affect the highest number of persons in the world and have the greatest potential to cause damages. When floods occur in less developed countries, they can result in thousands of deaths and lead to epidemics and also effectively end with decades of investment in infrastructure, seriously undermining economic prosperity.

To evaluate the CRFM tool, we simplified the CRP spreadsheet on flooding, reducing it to 20 questions considered essential for experts on the Brazilian scenario. The proposed model was based on Fuzzy Logic, which allows a more realistic evaluation. Each question corresponds to a Risk Factor (RF).

\subsection{Fuzzy relations}

The leading theory in quantifying uncertainty in scientific models from the late nineteenth century until the late twentieth century had been probability theory. However, the gradual evolution of the expression of uncertainty using probability theory was challenged, first in 1937 by Max Black, with his studies in vagueness, then with the introduction of fuzzy sets by Lotfi Zadeh in 1965. Zadeh's work had a profound influence on the thinking about uncertainty because it challenged not only probability theory as the sole representation for uncertainty, but also the very foundations upon which probability theory was based: classical binary (two-valued) logic [6].

Fuzzy Logic is a powerful tool to solve complex problems due to its ability to infer conclusions and produce answers based on vague, ambiguous and/or qualitatively incomplete or inaccurate information. In this respect, Fuzzy-based systems can reason similarly to human brain. Its behavior is represented in a natural and simple way, leading to the construction of understandable systems of easy maintenance. 
Traditionally, a logic proposition has two extremes: "totally true" or "totally false". However, in Fuzzy Logic, a premise varies in degrees of truthfulness from 0 to 1, leading to be "partially true" or "partially false". In the Fuzzy set theory, the groups are qualitatively labeled; using linguistic variables instead of numerical variables and the elements of such sets are characterized varying the degree of membership (value between 0 and 1 that indicates the degree to which an element belongs to the set). The models based on Fuzzy Logic do not substitute the models based on traditional logic, or the probabilistic models. Indeed, every "crisp" set is contained in a fuzzy set, but the opposite is not true. The introduction of the Fuzzy Logic enables the model to use qualitative and quantitative variables simultaneously and to generate quantitative results from qualitative data [7].

According to Zadeh [8], the greater the complexity of a system, the greater its efficiency in Fuzzy Logic, putting at a disadvantage other methods that cannot be modeled from inaccurate or ambiguous information. Fuzzy Logic was applied in the hierarchy model developed by Cosenza [9] which allows generating objective results from the simultaneous use of qualitative and quantitative variables. This model, although initially developed as a support tool in decision making in industrial location problems, was adapted in this study for the CRFM tool, to rate communities under risk of flooding.

\section{CRFM METHODOLOGY}

CRFM will depend on a set of inputs given by experts which are: definition of RFs and their relevance; determination of risk levels and RF rating in the communities.

\subsection{Definition of risk factors and their relevance}

To prepare the RF questionnaire, 20 questions were selected from the CRP spreadsheet to evaluate the tool based on the Brazilian reality. The experts assigned a degree of relevance to each selected question, as follows:

- Crucial (Cr) - The community may be seriously affected.

- Conditioning (Co) - The community may suffer significant damage.

- Little Conditioning (LC) - Minor damage.

- Irrelevant (Ir) - the community will hardly suffer damage.

The choice of four degrees of relevance $(\mathrm{Cr}, \mathrm{Co}, \mathrm{LC}, \mathrm{Ir})$ prevents the human tendency of choosing the central position when in doubt, impairing true judgment. The $20 \mathrm{RFs}$ and their respective degrees of relevance are described:

RF1 - Is the community in a river valley? $\mathrm{Cr}$

RF2 - Is the community located in a steep river basin? $\mathrm{Cr}$

RF3 - Is the community in a coastal area? Co

RF4 - Is the community located below the water level of a large water reserve (lake or sea) contained by a dike or a dam? Cr

RF5 - Is the community in an urban area (with large artificial impermeable surfaces)? $\mathrm{Cr}$

RF6 - Is the region or the upstream area subject to intense rain episodes? $\mathrm{Cr}$

RF7 - Is the region or the upstream area subject to long periods of rain? $\mathrm{Cr}$

RF8 - Are parts of the upstream soil naturally impervious? LC

RF9 - Has part of the upstream area been made impervious? (e.g. by building or paving the ground)? LC 
RF10 - Has upstream soil retention capacity been reduced by the removal of vegetation (e.g. for agricultural purposes or to provide fire wood)? LC

RF11 - Are parts of the city able to concentrate the water during heavy rain? (roads or street forming a canyon) Co

RF12 - Is part of the upstream area reserved for expansion fields (using empty areas as retention areas)? LC

RF13 - Is the river bed properly managed (i.e. cleared of materials that could form obstacles to flow)? $\mathrm{Cr}$

RF14 - Are buildings equipped to prevent flooding from the wastewater network? LC

RF15 - What is the human density of the area at risk? Co

RF16 - Has the community been flooded in the past? Co

RF17 - Is there warning in the case of flood? $\mathrm{Cr}$

RF18 - Are there flooding emergency response plans? Co

RF19 - Have areas of public health concern been identified? Co

RF20 - Are there sufficient shelters available if evacuation becomes necessary? $\mathrm{Cr}$

The RF set and their respective degrees of relevance may be modified according to the convenience of each decision maker. The model is flexible and allows incorporating or excluding factors.

\subsection{Risk factor determination}

This classification will rank the communities observing the requirements to counter the risk. These requirements were established by experts who determined four risk levels for the communities:

- Exceeds (A) - optimal conditions to counter the risk.

- Meets (B) - good conditions to counter the risk.

- Insufficient $(\mathrm{C})$ - bad conditions to counter the risk.

- None (D) - no conditions to counter the risk.

Dimensions and linguistic terms were established for each RF. This classification will clarify the leveling from the best to the worst scenario, i.e., from a situation of little risk to a situation of high risk:

\subsection{Risk factor classification in the communities}

In this paper, the tool was evaluated in the following neighbourhoods: Praça da Bandeira and Rio das Pedras in the city of Rio de Janeiro and Campos Elíseos in Duque de Caxias, all of them inside the hydrographical region of the Guanabara Bay, where the major flooding events and the highest population concentration are [10]. The chosen communities were compared with Table 1 and the RF ranges within which they are placed were determined. Table 2 shows the RFs and their relevance (Rel) and their rating in the communities (A - exceeds, B - meets, $\mathrm{C}$ - insufficient, and D - none):

From this point, the degrees of membership of each community for each RF will be increased or penalized according to the degree of relevance and the rating of the RF for the community. The membership matrix obeys the hierarchy model developed by Cosenza as given in Table 3. 
Table 1: Dimensions.

\begin{tabular}{|c|c|c|c|c|c|}
\hline $\mathrm{RF}$ & Unit & Exceeds (A) & Meets (B) & Insufficient (C) & None (D) \\
\hline RF1 & $\mathrm{Km}$ & $\geq 5$ & $2<x<5$ & $0.5<x<2$ & $\leq 0.5$ \\
\hline RF2 & $\mathrm{Km}$ & $\geq 5$ & $2<x<5$ & $0.5<x<2$ & $\leq 0.5$ \\
\hline RF3 & $\mathrm{Km}$ & $\geq 5$ & $2<x<5$ & $0.5<x<2$ & $\leq 0.5$ \\
\hline RF4 & $\mathrm{Km}$ & $\geq 5$ & $2<x<5$ & $0.5<x<2$ & $\leq 0.5$ \\
\hline RF5 & $\mathrm{Km}^{2}$ & $\leq 20$ & $20<x \leq 30$ & $30<x \leq 40$ & $>40$ \\
\hline RF6 & intense rain/year & $<3$ & $3 \leq x \leq 4$ & $5 \leq x \leq 6$ & $>6$ \\
\hline RF7 & long rain/year & $<3$ & $3 \leq x \leq 4$ & $5 \leq x \leq 6$ & $>6$ \\
\hline RF8 & $\%$ & $<20$ & $20 \leq x \leq 30$ & $30<x \leq 50$ & $>50$ \\
\hline RF9 & $\%$ & $<20$ & $20 \leq x \leq 30$ & $30<x \leq 50$ & $>50$ \\
\hline RF10 & $\mathrm{M}^{2}$ & $<5000$ & $5000 \leq \times \leq 8000$ & $8000<x \leq 10000$ & $>10000$ \\
\hline RF11 & unit & $<1$ & $1 \leq \times \leq 2$ & $2<x \leq 4$ & $>4$ \\
\hline RF12 & $\%$ & $>30$ & $20<x \leq 30$ & $10 \leq x \leq 22$ & $<12$ \\
\hline RF13 & maintenance/year & $>3$ & 3 & $<3$ & 0 \\
\hline RF14 & $\%$ & $>50$ & $20<x \leq 50$ & $10 \leq x \leq 20$ & $<10$ \\
\hline RF15 & people/Km² & $<12$ & $10 \leq x \leq 22$ & $22<x \leq 30$ & $>30$ \\
\hline RF16 & unit & $<1$ & $1 \leq \times \leq 3$ & $4 \leq \times \leq 5$ & $>5$ \\
\hline RF17 & alarms $/ \mathrm{Km}^{2}$ & $>3$ & $2 \leq x \leq 3$ & 1 & 0 \\
\hline RF18 & linguistics terms & Exceeds & Meets & Insufficient & None \\
\hline RF19 & unit & 0 & $1 \leq x \leq 3$ & $4 \leq \times \leq 5$ & $>5$ \\
\hline RF20 & unit & $>3$ & $2 \leq x \leq 3$ & 1 & 0 \\
\hline
\end{tabular}

Table 2: Communities.

\begin{tabular}{|c|c|c|c|c|}
\hline $\mathrm{RF}$ & Rel & Praça da Bandeira & Rio das Pedras & Campos Elíseos \\
\hline RF1 & $\mathrm{Cr}$ & $\mathrm{D}$ & A & $\mathrm{C}$ \\
\hline RF2 & $\mathrm{Cr}$ & $\mathrm{C}$ & $\mathrm{C}$ & A \\
\hline RF3 & Co & A & A & $\mathrm{A}$ \\
\hline RF4 & $\mathrm{Cr}$ & B & A & A \\
\hline RF5 & $\mathrm{Cr}$ & $\mathrm{D}$ & $\mathrm{C}$ & $\mathrm{D}$ \\
\hline RF6 & $\mathrm{Cr}$ & $\mathrm{D}$ & $\mathrm{C}$ & $\mathrm{B}$ \\
\hline RF7 & $\mathrm{Cr}$ & $\mathrm{D}$ & $\mathrm{C}$ & $\mathrm{C}$ \\
\hline RF8 & $\mathrm{LC}$ & $\mathrm{D}$ & $\mathrm{B}$ & $\mathrm{B}$ \\
\hline RF9 & $\mathrm{LC}$ & $\mathrm{C}$ & B & $\mathrm{C}$ \\
\hline RF10 & $\mathrm{LC}$ & $\mathrm{B}$ & $\mathrm{B}$ & $\mathrm{C}$ \\
\hline RF11 & Co & $\mathrm{D}$ & $\mathrm{C}$ & $\mathrm{D}$ \\
\hline RF12 & $\mathrm{LC}$ & $\mathrm{C}$ & $\mathrm{D}$ & $\mathrm{D}$ \\
\hline RF13 & $\mathrm{Cr}$ & $\mathrm{C}$ & B & $\mathrm{D}$ \\
\hline RF14 & $\mathrm{LC}$ & B & $\mathrm{D}$ & $\mathrm{D}$ \\
\hline RF15 & Co & $\mathrm{D}$ & $\mathrm{D}$ & $\mathrm{D}$ \\
\hline
\end{tabular}


Table 2: Continued.

\begin{tabular}{llccc} 
RF & Rel & Praça da Bandeira & Rio das Pedras & Campos Elíseos \\
\cline { 3 - 5 } RF16 & Co & D & D & D \\
RF17 & Cr & A & A & B \\
RF18 & Co & A & A & D \\
RF19 & Co & B & C & C \\
RF20 & Cr & A & A & B \\
\hline
\end{tabular}

Table 3: Membership matrix.

\begin{tabular}{lcccc}
\hline & A & B & C & D \\
\hline Cr & $1+4 / \mathrm{n}$ & 1 & $1-4 / \mathrm{n}$ & 0 \\
$\mathrm{Co}$ & $1+3 / \mathrm{n}$ & 1 & $1-3 / \mathrm{n}$ & $1 /(\mathrm{n}-16) !$ \\
$\mathrm{LC}$ & $1+2 / \mathrm{n}$ & 1 & $1-2 / \mathrm{n}$ & $1 /(\mathrm{n}-17) !$ \\
$\mathrm{Ir}$ & $1+1 / \mathrm{n}$ & 1 & $1-1 / \mathrm{n}$ & $1 /(\mathrm{n}-18) !$ \\
\hline
\end{tabular}

Table 4: Result.

\begin{tabular}{llll}
\hline RF & Praça da Bandeira & Rio das Pedras & Campos Elíseos \\
\hline RF1 & 0 & 1.2 & 0.8 \\
RF2 & 0.8 & 0.8 & 1.2 \\
RF3 & 1.15 & 1.15 & 1.15 \\
RF4 & 1 & 1.2 & 1.2 \\
RF5 & 0 & 0.8 & 0 \\
RF6 & 0 & 0.8 & 1 \\
RF7 & 0 & 0.8 & 0.8 \\
RF8 & 0.17 & 1 & 1 \\
RF9 & 0.9 & 1 & 0.9 \\
RF10 & 1 & 1 & 0.9 \\
RF11 & 0,04 & 0.85 & 0.04 \\
RF12 & 0.9 & 0.17 & 0.17 \\
RF13 & 0.8 & 1 & 0 \\
RF14 & 1 & 0.17 & 0.17 \\
RF15 & 0.4 & 0.4 & 0.4 \\
RF16 & 0.4 & 0.4 & 0.4 \\
RF17 & 1.2 & 1.2 & 1 \\
RF18 & 1.15 & 1.15 & 0.4 \\
RF19 & 1 & 0.85 & 0.85 \\
RF20 & 1.2 & 1.2 & 1 \\
PRL & 17.14 & 13.11 & 13.38 \\
\hline
\end{tabular}


Since $\mathrm{n}$ is equal to the number of RFs (20), the columns of the matrix will have the following degrees of membership: $\mathrm{A}=\{1.20 ; 1.15 ; 1.10 ; 1.05\}, \mathrm{B}=\{1 ; 1 ; 1 ; 1\}, \mathrm{C}=\{0.80$; $0.85 ; 0.90 ; 0.95\}, \mathrm{D}=\{0 ; 0.04 ; 0.17 ; 0.50\}$. Column A has degrees of membership higher than 1 , which is permitted by the model for a scenario that exceeds the expectations. Column $\mathrm{B}$ meets the expectations and has a degree of membership equal to 1. On the other hand, columns $\mathrm{C}$ and $\mathrm{D}$, were penalized for not meeting the expectations and have degrees of membership lower than 1. The degrees of membership of the communities for each RF will be added to obtain the Level of Risk Protection (PRL) for the community as given in Table 4.

After adding all the degrees of membership of the 20 RFs for each community, the community that obtained the lowest PRL is the most exposed to risk of flooding and therefore, the one that needs more investment from the government to reduce the degree of each RF and improve the population preparedness and resilience.

\subsection{Analysis of Results}

When we analyze the results of the CRFM tool applied to the three communities, we note that the neighboorhood Praça da Bandeira obtained the highest PRL $(17,14)$, while the Rio das Pedras community obtained the lowest $(13,11)$, practically tied with Campos Elíseos $(13,38)$ indicating that these last two communities have higher flooding vulnerability. Implicitly, the tool showed that the region where the level of human development is higher (Praça da Bandeira), is better prepared to face the risk. On the other hand, poorer communities with low educational level need greater investments to improve their infrastructure and raise the awareness of their inhabitants.

\section{CONCLUSION}

This study reviewed the importance of the APELL Programme of awareness and preparedness for emergencies at local level, that evaluates the communities by the Multi-Hazard Matrix, which is filled out by answering the questions in the CRP spreadsheet. The objective of this paper was to introduce a new tool that uses the Cosenza's Fuzzy Hierarchy Model, the CRFM that enables rating the communities exposed to risks.

The CRFM tool does not substitute the CRP spreadsheet. Using the Fuzzy Hierarchy Model in the communities with higher exposure to flooding risk led to a more realistic ranking process, identifying more fully and consistently the communities that require more investment. The Multi-Hazard Matrix continues to be filled by the CRP to assess the level of risk and vulnerability associated with the identified hazards. The results obtained through CRFM will depend on the following inputs: RFs considered in model structuring, importance assigned to those factors and the situation of the communities in face of the RFs. The opinion of experts is essential to ensure result reliability, because they are responsible for the model's inputs.

The CRFM tool was briefly introduced for the risk of flooding, but it can be used for all the risks in the Multi-Hazard Matrix and for all the RFs in the CRP spreadsheet. Model structuring makes it desirable preparing software that requires just to be provided with the inputs to give the result. Such software would greatly facilitate the application of CRFM, as well as simulating several situations where the environmental and structural conditions of a given community could be changed, which would be of interest of public managers to decide investment allocation and housing policies. The software would also make available a visual simulation to highlight the effects of a potential disaster. 


\section{REFERENCES}

[1] Sandres, G., Silva, C. \& Chavez, L., Instruments of support at emergency response planning in urban environment situated at the peripheral area around industrial facilities. SPE Annual Technical Conference and Exhibition. Society of Petroleum Engineers, 2008.

http://dx.doi.org/10.2118/114232-MS

[2] Knegtering, B. \& Pasman, H., Safety of the process industries in the 21st century: a changing need of process safety management for a changing industry. Journal of Loss Prevention in the Process Industries, 22(2), pp. 162-168, 2009. http://dx.doi.org/10.1016/j.jlp.2008.11.005

[3] Souza Júnior, A., Planejamento de emergência para acidentes industriais com conseqüências externas: experiência internacional e a situação brasileira, Phd thesis Universidade Federal do Rio de Janeiro, Rio de Janeiro, Brasil, 2002.

[4] United Nations Environment Programme (UNEP), Assessing the Vulnerability of Local Communities to Disasters: An Interactive Guide and Methodology - Community Risk Profile Tool. CRP Manual, available at http://www.unep.fr/shared/publications/pdf/ DTIx 1054xPA-CommunityRiskProfile.pdf

[5] United Nations Environment Programme (UNEP), APELL Multi-Hazard Training Kit for Local Authorities. APELL Manual, available at http://www.unep.fr/shared/ publications/pdf/DTIx1289xPA-APELLMulti-HazardTrainingKit.pdf

[6] Klir, J. \& Yuan, B., Fuzzy Sets and Fuzzy Logic: Theory and Applications, Prentice Hall: NJ, 1995.

[7] Cosenza, C. \& Toledo, O., Um caso de aplicação da Lógica Fuzzy - o Modelo CoppeCosenza de Hierarquia Fuzzy. XXIII Encontro Nacional de Engenharia de Produção, OuroPreto, Minas Gerais, Brasil, 2003.

[8] Zadeh, L., Fuzzy sets. Information and Control, 8(3), pp. 338-352, 1965. http://dx.doi.org/10.1016/S0019-9958(65)90241-X

[9] Cosenza, C., Localização Industrial: delineamento de uma metodologia para a hierarquização das potencialidades regionais, Universidade Federal do Rio de Janeiro, 1998.

[10] CEPED, available at http://www.ceped.ufsc.br/atlas-brasileiro-de-desastres-naturais1991-a-2012/ 